\title{
Pulmonary deposition of nebulised amiloride in cystic fibrosis: comparison of two nebulisers
}

\author{
S H L Thomas, M J O'Doherty, A Graham, C J Page, P Blower, D M Geddes, \\ T O Nunan
}

\begin{abstract}
Background Preliminary evidence suggests that regular inhalation of nebulised amiloride reduces sputum viscoelasticity, increases the clearance of sputum by mucociliary mechanisms and by coughing and reduces the rate of deterioration in lung function in patients with cystic fibrosis. These effects depend on adequate delivery of amiloride to the airways. This study was performed to quantify and compare pulmonary deposition of amiloride produced by two different nebuliser systems.

Methods The pulmonary deposition of nebulised amiloride (1 $\mathrm{mg}$ in $3 \mathrm{ml}$ saline) was measured in eight patients with cystic fibrosis when given via a jet (System 22 with CR 60 compressor) and an ultrasonic (Fisoneb) nebuliser. Human serum albumin labelled with technectium-99m was used as an indirect marker for amiloride and its deposition in the lung was detected with a gamma camera.
\end{abstract}

Results Amiloride inhalation caused no side effects or changes in spirometric indices. The mean (SD) total pulmonary amiloride deposition was 57 (24) $\mu \mathrm{g}$ with the System 22 and 103 (53) $\mu$ g with the Fisoneb nebuliser. Pulmonary deposition was completed more rapidly with the Fisoneb (4-5 minutes) than with the System 22 nebuliser (7-8 minutes) and the Fisoneb was preferred by the patients.

Conclusions Both nebulisers appeared to deliver adequate amounts of amiloride to the lungs, but treatment with the Fisoneb nebuliser was quicker, more efficient, and more acceptable to the patients. Of the two nebulisers assessed, the Fisoneb would be preferred for clinical trials.

Cystic fibrosis is associated with increased sodium absorption, reduced chloride conductance, and an increased potential difference across the respiratory epithelium. ${ }^{12}$ These abnormalities may contribute to the pathogenesis of the disease by reducing the water content of the airway surface liquid, ${ }^{3}$ thus impairing mucociliary clearance. Topically applied amiloride blocks entry of sodium into respiratory epithelial cells and reduces the potential difference of the airway epithelium towards normal in patients with cystic fibrosis.
This may improve the hydration of the surface liquid. ${ }^{4}$ Preliminary evidence from patients with cystic fibrosis suggests that nebulised amiloride reduces sputum viscosity and elasticity and produces transient improvements in the clearance of sputum by mucociliary mechanisms and by coughing, ${ }^{5}$ and that regular inhalation reduces the rate of deterioration in forced vital capacity. ${ }^{6}$

The efficacy of nebulised amiloride will depend on the delivery of sufficient quantities of the drug to the airway surface. In sheep the effects of amiloride on the potential difference of the airway epithelium are dose related, maximal effects occurring at high airway surface liquid concentrations; ${ }^{7}$ the drug is then cleared rapidly from this site, resulting in a short duration of action. ${ }^{78} \mathrm{~A}$ high initial airway surface concentration of amiloride is therefore likely to be needed to maintain a therapeutic effect between inhalations, and this will require an efficient method of aerosol administration.

In this study we compared the pulmonary deposition of amiloride nebulised from two apparently suitable nebuliser systems. ${ }^{7}$ The aim of the study was to determine how much amiloride was delivered to the lungs from each system and which nebuliser would be more suitable for use in clinical trials of amiloride.

\section{Methods}

NEBULISERS

The nebulisers selected for the study were System 22 Acorn (Medic-Aid Ltd), a jet nebuliser driven by an air compressor (CR 60, Medic-Aid Ltd) in common use for delivery of nebulised antibiotics, and Fisoneb (Fisons/ Medix), a portable hand held ultrasonic nebuliser. Minor modification of the Fisoneb mouthpieces was needed so that a filter could be fitted over the expiratory port to prevent escape of radiolabelled aerosol (additional deadspace $15 \mathrm{ml}$ ). The Fisoneb was run at its midpoint setting.

VALIDATION OF THE AMILORIDE MARKER In the absence of a suitable radiolabelled amiloride analogue, an indirect marker ${ }^{99 \mathrm{~m}} \mathrm{Tc}$ colloidal human serum albumin $\left({ }^{99 \mathrm{~m}} \mathrm{Tc}\right.$ HSA, Venticoll)) had to be used to estimate deposition of amiloride in the lung. For this approach to be valid the marker should not affect the mass output of nebulised amiloride or the particle size output of the nebuliser, and it should be distributed in the aerosol cloud like amiloride. This was assessed by 
measuring the mass output of the System 22 Acorn nebuliser by nebulising amiloride solution to dryness in the presence and absence of ${ }^{99} \mathrm{~m}$ Tc HSA and capturing the aerosol cloud by means of a preimpinger and filter. A similar study was not performed for the Fisoneb nebuliser as the output of ultrasonic nebulisers is underestimated if measured without a subject breathing from the mouthpiece. The amiloride content of washings from the preimpinger and filter (cloud recovery) and nebuliser was measured by spectrophotometry $(361 \mathrm{~nm})$. The particle size of the output of amiloride solution from both nebulisers was measured in the presence and absence of ${ }^{99 \mathrm{~m}} \mathrm{Tc}$ HSA with a Malvern Master laser particle sizer. An amiloride solution containing ${ }^{99 \mathrm{~m}} \mathrm{Tc}$ HSA was nebulised and the cloud sampled with a nine stage cascade impactor. Activities associated with filters from each stage of the cascade impactor (representing particles of different size ranges) were compared with the concentrations of amiloride in washings from these filters. The amiloride content of the filters was determined by gradient high pressure liquid chromatography, $0 \cdot 1 \%$ trifluoroacetic acid in water and $0.1 \%$ trifluoroacetic acid in acetonitrile being used. With a flow rate of $2 \mathrm{ml} / \mathrm{min}$ amiloride was eluted as a sharp peak at 3.4 minutes, and there was a linear relation between amiloride content and the amiloride peak integral. The mean extraction efficiency of amiloride from the filters was $55 \%$ (SD 5\%) and was independent of the initial loading concentration.

\section{MEASUREMENT OF PULMONARY AMILORIDE DEPOSITION}

Eight adults (six male, two female) with cystic fibrosis volunteered to take part and each gave written informed consent. The study was approved by the ethics committees of the West Lambeth Health District and the Royal Brompton and National Heart Hospital. Each subject was studied on two occasions, with the System 22 on one occasion and Fisoneb on the other. Nebulisers were allocated in random order. Before aerosol inhalation dynamic (five second counting frames) xenon-133 ventilation scanning was performed during breath holding, at equilibrium, and during washout for measurement of total and regional ventila-

Table 1 Mean (SD) particle sizes and mass output of a $3 \mathrm{ml}$ solution of amiloride in water, with and without the addition of ${ }^{99 m}$ T c human serum albumin (HSA), with the two nebulisers

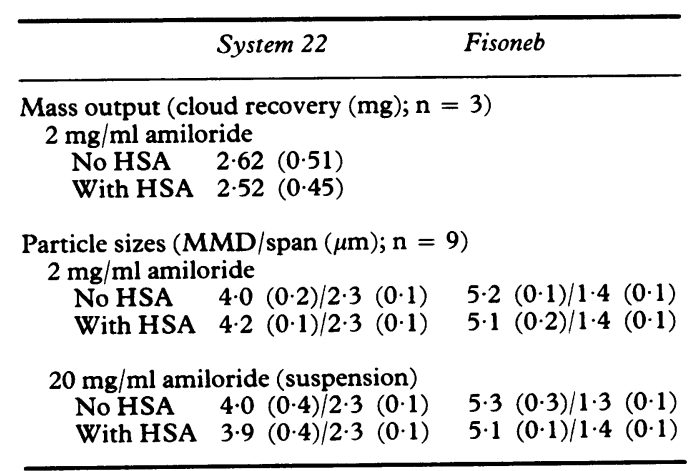

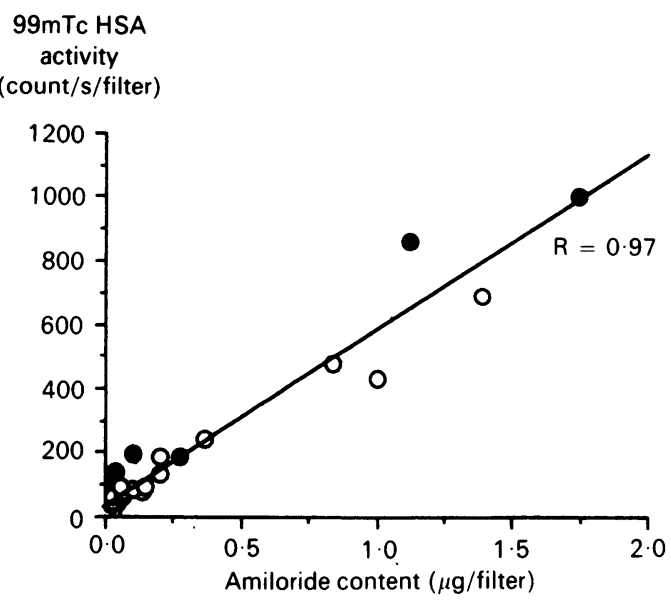

Figure 1 Relation between technetium-99m labelled human serum albumin ( ${ }^{99 m}$ Tc $H S A$ ) activity and amiloride content in cascade impactor filters with the Fisoneb ( ) and System 22 ( ) nebulisers.

tion. The patients then inhaled aerosol from a nebuliser solution consisting of amiloride $1 \mathrm{mg}$ and ${ }^{99 \mathrm{~m}} \mathrm{Tc} \mathrm{HSA} 50 \mu \mathrm{g}(37 \mathrm{MBq})$ in a total volume of $3 \mathrm{ml}$ (amiloride concentration $1 \mathrm{mmol} / \mathrm{l})$. During inhalation dynamic scans of the lungs were performed (posterior projection) for measurement of dynamic deposition of aerosol in the lungs. After inhalation static scans were taken of the lungs (anterior and posterior), oropharynx (lateral), and abdomen (anterior and posterior), nebuliser apparatus, and expiratory port filter.

Pulmonary amiloride deposition was calculated from the posterior and anterior lung counts with geometric corrections derived from lung phantom studies. ${ }^{9-11}$ The fractional exchange of air was calculated on the basis of the Stewart-Hamilton principle, ${ }^{12}$ by dividing the ${ }^{133} \mathrm{Xe}$ counts at the end of the equilibrium phase by the area under the ${ }^{133} \mathrm{Xe}$ activity-time curve during washout from time zero extrapolated to infinity. The ${ }^{133} \mathrm{Xe}$ counts were corrected for tissue background on the basis of the activity measured over both shoulders. Spirometry was performed before and after aerosol inhalation.

\section{ANALYSIS}

All statistical comparisons were made by using a repeated measures analysis of variance. A p value below 0.05 was taken as significant.

\section{Results}

The addition of ${ }^{99} \mathrm{~m} \mathrm{Tc}$ HSA to the nebuliser solution did not effect nebuliser mass output or particle size characteristics (table 1). The marker was distributed in particles of differing size ranges in the same way as amiloride (fig 1).

The distribution of ${ }^{133} \mathrm{Xe}$ during breath holding and at equilibrium and the aerosol deposition scans taken from the same patient after each nebuliser had been used are shown in figure 2. Patchy ventilation and aerosol deposition were observed in all patients. The mean (SD) fractional exchange of air during tidal respiration, a measure of regional ventilation, was $1.32(0.81) \% / \mathrm{s}$ in the right lung and 1.36 
Figure 2 Xenon-133 ventilation scans taken during breath hold $(A)$ and at equilibrium $(B)$, with scans showing deposition of technetium99 m labelled human serum albumin aerosol from the same patient after

inhalation from System 22

(C) and Fisoneb (D) nebulisers.

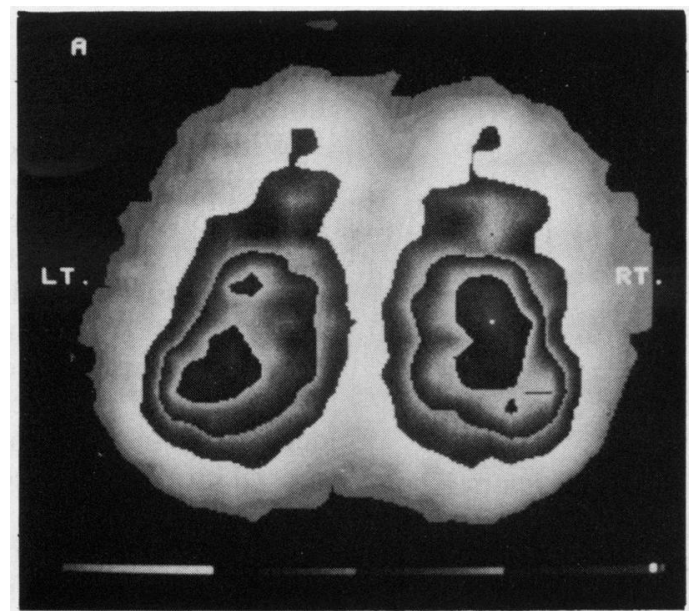

(A)

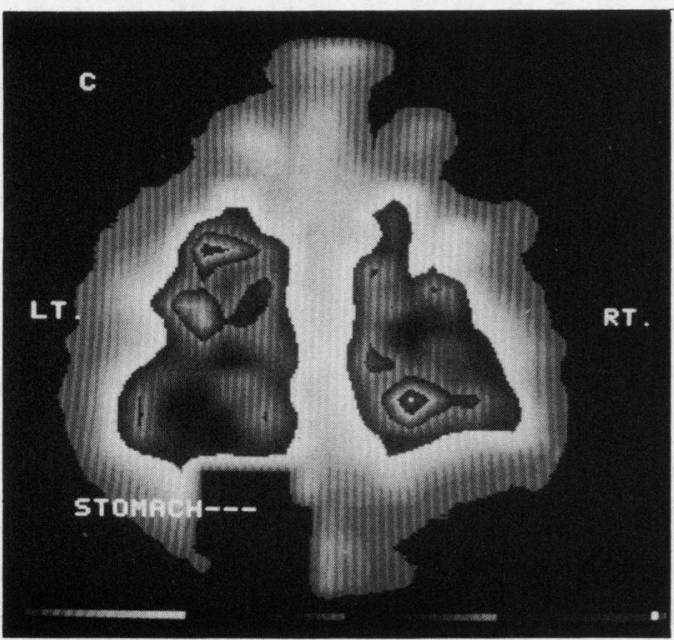

(C)

$(0.92) \% / s$ in the left lung (normal right lung value $\left.3 \cdot 18(1 \cdot 56) \% / \mathrm{s}^{12}\right)$; ventilation was greater in the lower than in the upper zones (for example, for the right lung: $1.63(0.91) v 0.94$ $(0.61) ; \mathrm{p}<0.005)$.

Table 2 Deposition and fate (mean (SD) values) of $1 \mathrm{mg}$ amiloride in a $3 \mathrm{ml}$ nebuliser solution with the two nebulisers

\begin{tabular}{|c|c|c|c|}
\hline & \multicolumn{2}{|l|}{ Nebuliser } & \multirow[b]{2}{*}{$p^{\star}$} \\
\hline & System 22 & Fisoneb & \\
\hline $\begin{array}{l}\text { Pulmonary deposition } \\
\text { Total (both lungs) } \\
\text { Right lung } \\
\text { Left lung }\end{array}$ & $\begin{array}{ll}57 & (24) \\
31 & (15) \\
27 & (10)\end{array}$ & $\begin{aligned} 103 & (53) \\
53 & (31) \\
49 & (25)\end{aligned}$ & $\begin{array}{l}0.047 \\
\text { NS } \\
0.034\end{array}$ \\
\hline $\begin{array}{l}\text { Regional deposition (ri } \\
\text { Central } \\
\text { Peripheral } \\
\text { Upper } \\
\text { Lower }\end{array}$ & $\begin{aligned} \text { Ing only): } & \\
7.2 & (3.8) \\
23.6 & (12 \cdot 1) \\
5.4 & (2.9) \\
10.6 & (5.9)\end{aligned}$ & $\begin{array}{ll}15.6 & (9 \cdot 8) \\
37.9 & (23 \cdot 1) \\
11.8 & (7 \cdot 4) \\
13.9 & (10 \cdot 7)\end{array}$ & $\begin{array}{l}0.041 \\
\text { NS } \\
0.036 \\
\text { NS }\end{array}$ \\
\hline $\begin{array}{l}\text { Deposition ratios }\left({ }^{133} \mathrm{X}\right. \\
\text { Central: peripheral } \\
\text { Upper: lower }\end{array}$ & $\begin{array}{l}\text { ected): } \\
\qquad \begin{array}{ll}3.7 & (1 \cdot 1) \\
0.99 & (0.34)\end{array}\end{array}$ & $\begin{array}{ll}4.9 & (2.5) \\
2.25 & (1.66)\end{array}$ & $\begin{array}{l}\text { NS } \\
\text { NS }\end{array}$ \\
\hline $\begin{array}{l}\text { Extrapulmonary depos } \\
\text { Oropharynx } \\
\text { Stomach } \\
\text { Exhalation filter }\end{array}$ & $\begin{array}{cc}\text { counts/s): } \\
329 & (219) \\
406 & (151) \\
5177 & (765)\end{array}$ & $\begin{array}{rr}902 & (1124) \\
992 & (552) \\
5390 & (3378)\end{array}$ & $\begin{array}{l}\text { NS } \\
0 \cdot 012 \\
\text { NS }\end{array}$ \\
\hline $\begin{array}{l}\text { Nebuliser counts (cour } \\
\text { Before nebulisation } \\
\text { After nebulisation }\end{array}$ & $\begin{array}{ll}\left.10^{-3}\right): & \\
20.52 & (0.91) \\
11 \cdot 18 & (0.91)\end{array}$ & $\begin{aligned} 19.95 & (1.47) \\
8.65 & (1.42)\end{aligned}$ & $\begin{array}{l}\text { NS } \\
0.002\end{array}$ \\
\hline
\end{tabular}

^Analysis of variance.

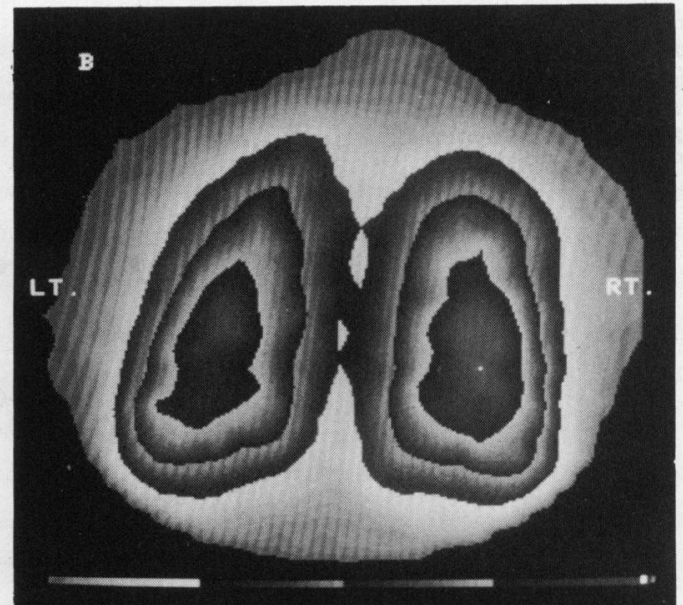

(B)

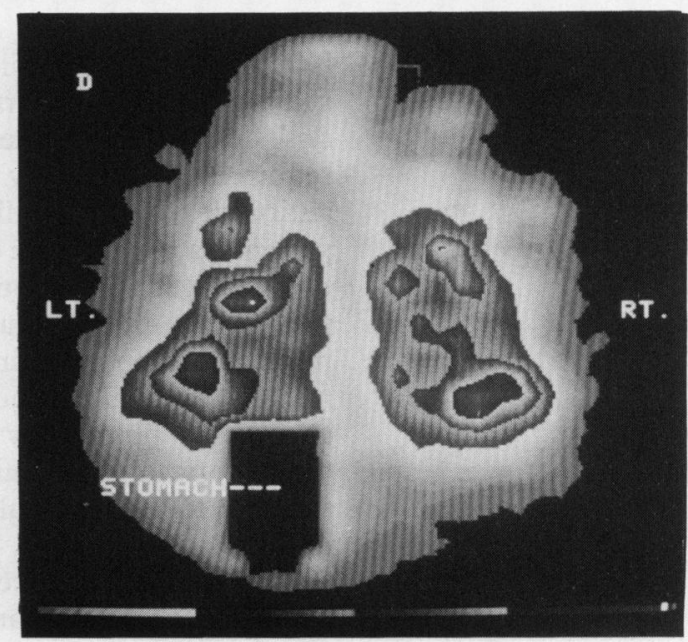

(D)

Dynamic lung scans performed during aerosol inhalation (fig 3) showed that deposition of amiloride occurred more rapidly and was completed sooner with the Fisoneb nebuliser (4-5 minutes) than with System 22 nebuliser (6-7 minutes). The total amount of amiloride deposited at the end of the inhalation period was greater with the Fisoneb than with the System 22 nebuliser and this was the case for all lung regions (table 2), especially the central and upper zones. The ratio of central to peripheral deposition (corrected for volume differences on the basis of the ${ }^{133} \mathrm{Xe}$ counts from each region) did not differ significantly between the two nebulisers (table 2), but deposition of amiloride in the oropharynx and stomach was greater with the Fisoneb nebuliser (table 2).

$\mathrm{FEV}_{1}, \mathrm{FVC}$, and PEF did not change significantly after amiloride inhalation with either nebuliser (table 3 ), and no adverse effects of the inhalations were reported by the patients. The patients preferred the Fisoneb because it was less noisy than the CR 60 compressor used with System 22.

\section{Discussion}

In this study we compared the pulmonary deposition of amiloride when given via two apparently suitable nebulisers. These were selected because desirable features of nebul- 
Figure 3 Dynamic deposition of radioaerosol in peripheral lung during aerosol inhalation (mean and $S E$ values) with the Fisoneb and System 22 nebulisers.

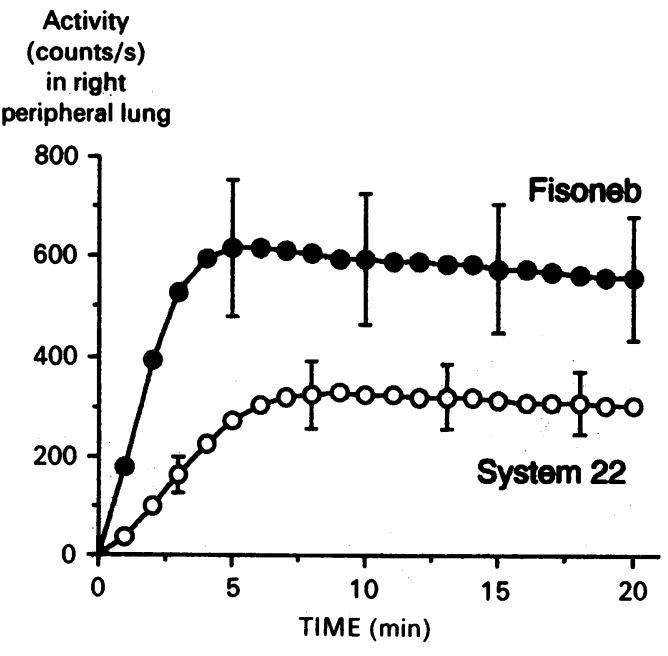

isers for inhaling amiloride were thought to include a light and portable design with rapid dose delivery, as frequent doses are likely to be required; suitability for administering antibiotics as these will also be used by many patients; a particle size output in the range 3-8 $\mu \mathrm{m}$, which is small enough to minimise deposition in the upper airways and large enough to minimise deposition in and beyond the terminal bronchii ${ }^{13}$; and the production of adequate pulmonary deposition for a therapeutic effect. Previous studies ${ }^{14}$ suggested that the Fisoneb nebuliser met most of these criteria because it is hand held and easily portable and produces a rapid output of appropriately sized particles. The System 22 with a CR60 compressor was also studied because it is issued to many patients with cystic fibrosis for administration of antibiotic prophylaxis and bronchodilators, though it is less portable and thus less attractive for frequent treatments. Only one nebuliser, the System 22 Mixer, is substantially more efficient than those tested here, ${ }^{914} 15$ but it is bulky and thus probably impractical for amiloride treatment.

We assessed the pulmonary deposition of nebulised amiloride with ${ }^{99 \mathrm{~m}} \mathrm{Tc}$ HSA as an indirect marker as this did not affect the output of the nebuliser and was distributed in the aerosol cloud in the same way as amiloride. Similar methods have been used to measure the deposition of other agents. ${ }^{911} 1415$ Our patients had severe airways disease as indicated by abnormal spirometric values, greatly reduced fractional exchange of air, and uneven regional ventilation. Deposition of aerosol in the lungs was patchy and, as expected, was less in poorly

Table 3 Effects of inhaled amiloride on lung function: mean values (SD) before and after amiloride with the two nebulisers

\begin{tabular}{|c|c|c|c|}
\hline & & System 22 & Fisoneb \\
\hline $\begin{array}{l}\text { FVC (1) } \\
\text { (Predicted 3.20 (0.24) l) }\end{array}$ & $\begin{array}{l}\text { Before } \\
\text { After }\end{array}$ & $\begin{array}{ll}2.02 & (0.85) \\
1.95 & (0.68)\end{array}$ & $\begin{array}{ll}2.10 & (1.06) \\
2 \cdot 16 & (1.24)\end{array}$ \\
\hline $\begin{array}{l}\mathrm{FEV}_{1}(1) \\
\text { (Predicted 2.78 (0.24) 1) }\end{array}$ & $\begin{array}{l}\text { Before } \\
\text { After }\end{array}$ & $\begin{array}{ll}1.47 & (0.82) \\
1.39 & (0.77)\end{array}$ & $\begin{array}{ll}1.39 & (0.73) \\
1.37 & (0.67)\end{array}$ \\
\hline $\begin{array}{l}\operatorname{PEF}\left(1 \mathrm{~min}^{-1}\right) \\
\left(\text { Predicted } 418(61) 1 \mathrm{~min}^{-1}\right)\end{array}$ & $\begin{array}{l}\text { Before } \\
\text { After }\end{array}$ & $\begin{array}{ll}281 & (87) \\
277 & (77)\end{array}$ & $\begin{array}{ll}282 & (94) \\
272 & (96)\end{array}$ \\
\hline
\end{tabular}

For all before versus after amiloride and System 22 versus Fisoneb comparisons $p>0.05$ (NS) by analysis of variance. ventilated regions. This confirmed previous reports in children ${ }^{16}$ and adults ${ }^{11}{ }^{17}$ with cystic fibrosis.

With both nebulisers the total amount of amiloride deposited was similar to that seen in association with a short lived effect in dogs and humans, ${ }^{518}$ though a lower nebuliser dose was used. The Fisoneb delivered more drug within a shorter time (five minutes) than the System 22 Acorn. It was preferred by the patients because it is quiet and compact. The increased aerosol deposition in the oropharynx, stomach, and central lung region associated with the Fisoneb probably occurs as a consequence of the larger particle sizes produced by this nebuliser. Although more aerosol was swallowed the estimated gastrointestinal dose is unlikely to have a measurable diuretic effect even if completely absorbed. In this study the Fisoneb nebuliser was used at a midpoint setting: use at its maximum setting might reduce nebulisation time but the effects of this on pulmonary aerosol deposition have not been studied.

We cannot say whether therapeutic concentrations of amiloride were achieved in the airways in this study as no pharmacodynamic measurements were made. Experiments in animals and humans suggest that amiloride affects epithelial potential difference and mucociliary clearance over a concentration range of $0 \cdot 1 \mu \mathrm{mol} / 1$ to $1 \mathrm{mmol} / 1 .{ }^{47}$ It has been estimated that, because of rapid drug clearance, a concentration of at least $5 \mathrm{mmol} / 1$ would be required to produce detectable effects lasting five hours. ${ }^{6}$ In the clinical study that showed that the deterioration in forced vital capacity of patients with cystic fibrosis could be slowed by the regular administration of inhaled amiloride, ${ }^{6}$ however, the dose and nebuliser system used produced an airways surface concentration of only $0.08 \mathrm{mmol} / 1 .^{8}$ Relating these concentrations to a figure for total amiloride deposition is difficult, but in dogs a total deposition of $31 \mu \mathrm{g}$ was associated with an airways surface concentration of amiloride of $0.03-0.12 \mathrm{mmol} / 1,{ }^{18}$ and in humans a total deposition of $70 \mu \mathrm{g}$ produced significant but short lived effects on mucociliary clearance. ${ }^{5}$ It seems likely, therefore, that a total deposition substantially greater than $70 \mu \mathrm{g}$ should be aimed for. The mean amiloride deposition of $102 \mu \mathrm{g}$ achieved by the Fisoneb under the conditions used in this study probably does not represent a large enough improvement to be associated with a more prolonged effect.

A higher nebuliser dose of amiloride would give greater deposition and probably a larger and more prolonged therapeutic effect. The maximum concentration of amiloride that can be used in nebuliser solutions is limited by its solubility to about $5 \mathrm{mmol} / 1$ in saline ${ }^{7}$ and, although concentrations of $20 \mathrm{mmol} / 1$ can be achieved in water, ${ }^{7}$ this has been avoided as hypotonic solutions may provoke bronchoconstriction. ${ }^{19}$ The amiloride dose could also be increased by giving a larger volume, but this would take longer to nebulise. A $6.8 \mathrm{mg}$ dose could be given as $4.5 \mathrm{ml}$ of $5 \mathrm{mmol} / 1$ solution. This might produce up to 10 times the deposition found in this study because of the higher 
amiloride dose and because of the increased efficiency of nebulising larger volumes, ${ }^{9}$ but each treatment would take longer.

Airway abnormalities associated with cystic fibrosis, including gland hypertrophy, duct obstruction and bronchiectasis, have been reported in early infancy. ${ }^{20}$ If amiloride has a beneficial preventive effect treatment should logically begin during infancy. Aerosol deposition in infants and children may be affected by different respiration characteristics and the need to use a face mask, so further studies are needed in this age group.

If the clinical benefit suggested by the pilot study is confirmed by larger scale clinical trials, nebulised amiloride may become an important treatment for patients with cystic fibrosis. It would be unfortunate if spuriously negative results were obtained because of inadequate amiloride deposition in the lungs resulting from inefficient nebuliser apparatus or poor compliance by patients. It is important to perform studies such as the one described here before we embark on costly and time consuming clinical trials. The deposition efficiency of other potential methods of administration, such as dry powder inhalation or use of metered dose inhalers, should also be assessed.

1 Knowles MR, Gatzy JT, Boucher RC. Increased bioelectric potential difference across respiratory epithelia in cystic fibrosis. N Engl J Med 1981;305:1489-95.

2 Boucher RC, Cotton CU, Gatzy JT, Knowles MR, Yankaskas JR. Evidence for reduced $\mathrm{Cl}^{-}$permeability and increased $\mathrm{Na}^{+}$permeability in cystic fibrosis human primary cell cultures. J Physiol (Lond) 1988;405:77-103.

3 Potter JL, Mathews LW, Spector S, Lemm J. Studies on pulmonary secretions. II. Osmolarity and the ionic environment of pulmonary secretions from patients with cystic fibrosis, bronchiectasis, and laryngectomy. Am Rev Respir Dis 1967;96:83-7.

4 Knowles MR, Murray G, Shallal J, Askin F, Ranga V, Gatzy $\mathrm{J}$, et al. Bioelectric properties and ion flow across excised human bronchi. J Appl Physiol 1984;56:868-77.

5 App EM, King $M$, Helfesrieder R, Kohler D, Mattys $H$. Acute and long-term amiloride inhalation in cystic fibrosis disease. Am Rev Respir Dis 1990;141:605-12.

6 Knowles MR, Church NL, Walter WE, Yankaskas JR, Gilligan P, King $M$, et al. A pilot study of aerosolized amiloride for the treatment of lung disease in cystic fibrosis. N Engl J Med 1990;322:1189-94.

7 Mentz WM, Brown JB, Friedman M, Stutts MJ, Gatzy JT, Boucher RC. Deposition, clearance, and effects of aerosolized amiloride in sheep airways. Am Rev Respir Dis 1986;134:938-43.

8 Waltner WE, Church NL, Gatzy JT, Boucher RC, Knowles MR. Deposition, pharmacokinetics, and toxicity of amiloride aerosol in normal and cystic fibrosis (CF) subjects [abstract]. Am Rev Respir Dis 1987;135 (suppl):A288.

9 O'Doherty M, Thomas S, Page C, Bradbeer CS, Nunan T, Bateman N. Pulmonary deposition of nebulised pentamidine. The effect of nebuliser type, dose, and volume of fill. Thorax 1990;45:460-4.

10 Ruffin RE, Dolovitch MB, Wolff RK, Newhouse MT. The effects of preferential deposition of histamine in the human airway. Am Rev Respir Dis 1978;117:485-91.

11 Newman SP, Woodman G, Clarke SW. Deposition of carbenicillin aerosol in cystic fibrosis: effects of nebuliser system and breathing pattern. Thorax 1988;43:318-22.

12 Secher-Walker RH, Hill RI, Markham J, Baker J, Wilhelm $\mathrm{J}$, Alderson PO, et al. The measurement of regional ventilation in man: a new method of quantification. $J$ Nucl Med 1973;14:725-32.

13 Clarke SW. Inhaler therapy. $Q J$ Med 1988;67:355-68.

14 Thomas SHL, O'Doherty MJ, Page CM, Nunan TO, Bateman NT. Which apparatus for inhaled pentamidine? A comparison of pulmonary deposition via eight nebulisers. Eur Respir J 1991;4:616-22.

15 O'Doherty MJ, Thomas S, Page C, Bradbeer C, Barlow D, Nunan TO, et al. Differences in the relative efficiency of nebulisers for pentamidine administration. Lancet 1988;ii: 1283-6.

16 Alderson PO, Secher-Walker RH, Stominger DB, Markham BS, Hill RL. Pulmonary deposition of aerosols in children with cystic fibrosis. J Pediatr 1974;84:479-84.

17 Ilowite JS, Gorvoy JD, Smaldone GC. Quantitative deposition of aerosolized gentamicin in cystic fibrosis. Am Rev Respir Dis 1987;136:1445-9.

18 Boucher RC, James MK, Friedman M, Stutts MJ, Fullton J, Gatzy JT. Acute cardiovascular and pulmonary effects of intravenous and aerosolized amiloride in the dog. Toxicol Appl Pharmacol 1987;87:264-75.

19 Shoeffel RE, Anderson SD, Altounyan REC. Bronchial hyperreactivity in response to inhalation of ultrasonically nebulised solutions of distilled water and saline. $B M J$ 1981;283:1285-7.

20 Elborn JS, Shale DJ. Lung injury in cystic fibrosis. Thorax 1990;43:970-3 